\title{
Geographical information systems and tropical medicine
}

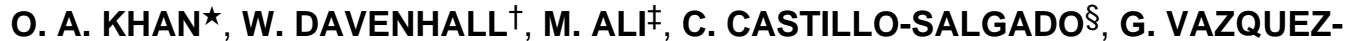 \\ PROKOPECף, U. KITRON ${ }^{\Uparrow, \star \star}$, R. J. SOARES MAGALHÃES ${ }^{\dagger \dagger}$, and A. C. A. CLEMENTS ${ }^{\dagger \dagger}$, \\ ^Department of Family Medicine, University of Vermont, 235 Rowell, Burlington, VT 05405, \\ U.S.A., Department of Family Medicine, University of Pennsylvania, 3400 Spruce Street, \\ Philadelphia, PA 19104, U.S.A., and Christiana Care Health System, 1309 Veale Road, \\ Wilmington, DE 19810, U.S.A
}

†ESRI, Inc., 380 New York Street, Redlands, CA 92373-8100, U.S.A

\#International Vaccine Institute, Seoul National University Research Park, San 4-8 Nakseoungdae-dong, Gwanakgu, Seoul, 151-191, South Korea

§Pan American Health Organization, 525 23rd Street NW, Washington, DC 20037, U.S.A., and Department of Epidemiology, Bloomberg School of Public Health, Johns Hopkins University, 615 N Wolfe Street, Baltimore, MD 21205, U.S.A

IDepartment of Environmental Studies, Emory University, Atlanta, GA 30322, U.S.A

${ }^{\star \star}$ Fogarty International Center, National Institutes of Health, Bethesda, MD 20892-2220, U.S.A

†tUniversity of Queensland, School of Population Health, Herston Road, Herston, Queensland 4006, Australia

¥¥Australian Centre for International and Tropical Health, Queensland Institute of Medical Research, Herston, Queensland 4006, Australia

\section{Abstract}

In terms of their applicability to the field of tropical medicine, geographical information systems (GIS) have developed enormously in the last two decades. This article reviews some of the pertinent and representative applications of GIS, including the use of such systems and remote sensing for the mapping of Chagas disease and human helminthiases, the use of GIS in vaccine trials, and the global applications of GIS for health-information management, disease epidemiology, and pandemic planning. The future use of GIS as a decision-making tool and some barriers to the widespread implementation of such systems in developing settings are also discussed.

\begin{abstract}
Among the contributions that geographical information systems (GIS) make to the field of tropical medicine, their use in detection analysis, geographical visualization, communication and reporting is critical. Over the last decade, GIS have leveraged the power of several important technological innovations, all of which contribute to the increasing role of such systems in public health. These innovations include the wider use and growing capacity of the internet, satellite-based global positioning systems (GPS), various tools for data generation/capture (from satellite imagery to hand-held devices that permit geographically relevant data to be collected and analysed in field settings), and computer software and
\end{abstract}

\footnotetext{
(C) W. S. Maney \& Son Ltd 2010

Reprint requests to: O. A. Khan, Christiana Care Health System, 1309 Veale Road, Wilmington, DE 19810, U.S.A. omar.khan@vtmednet.org.
} 
hardware that allow complex data analysis even in environments that are relatively resourcepoor.

The advent of cloud computing (i.e. the virtual, wireless integration of information systems and special-purpose computing) combined with more robust GIS components (hardware and software), better-trained staff, and higher-quality, more accessible data, have led to a distributed, virtual process. With their intrinsic capacity to define geographical location with a high degree of certainty and accuracy, GIS have emerged as powerful, collaborative, information tools that cut across the work of public health. Such systems are especially useful to the disciplines of disease surveillance, detection and tracking. They have particular relevance to studies of vector-borne disease, allowing mapping of vector, reservoir, vertebrate host and environment in a coherent way, facilitating visualization and the development of explanatory and predictive models.

GIS have been utilized in many different ways, from identifying geographical locations containing potential threats to identifying the geographical patterns of an outbreak. They can also be instrumental in helping to determine the geographical scope of populations at risk, identifying specific geographical clusters of vulnerable people, and determining good geographical locations for the storage and administration of vaccines. Examples of the collaborative nature of today's GIS include their use in efforts to strengthen the international plans for, and responses to, global threats such as severe acute respiratory syndrome (SARS), and avian and H1N1 influenza.

While GIS are traditionally associated with specialised software and powerful, purpose-built computers, their future may well lie in leveraging a host of new, geographically-enabled data sources, from relational databases created by large organizations to single users streaming data from personal, cellular devices. The geographical data that have been created and shared using universal standards for such information have contributed to geographical 'inter-operability' around the globe. For example, over 111 national health ministries (representing 58\% of all the nations of the world) have adopted GIS software technology in their disease surveillance, creating one of the largest, focussed networks, of GIS users involved in public health/tropical medicine.

Described below are some specific case studies that demonstrate the utility of GIS in a variety of settings relevant to tropical medicine.

\section{GIS AND REMOTE SENSING FOR DISEASE MAPPING: THE EXAMPLE OF CHAGAS DISEASE}

The transmission dynamics of a vector-borne disease depend on the co-occurrence of susceptible vertebrate hosts (which may include humans) and infected vectors within the bounds of a permissive environment (Kitron, 1998; Reisen, 2010). In the vector-borne diseases of humans, heterogeneities in the occurrence and competence of the vectors and any 'reservoir' hosts, together with local variations in vector feeding patterns, herd immunity in the vertebrate hosts, the infectiousness of the hosts, the demographic and socioeconomic patterns of the local human populations, climate and other environmental variables strongly modulate the likelihood and intensity of transmission (Kitron, 1998; Reisen, 2010). As a consequence, vector-vertebrate contacts are not random but highly heterogeneous over space and time. GIS, coupled with rigorous spatial analysis and remotely sensed data (i.e. satellite-derived and spatially continuous proxies of environmental factors), can not only provide insights about the factors and mechanisms responsible for the heterogeneous contacts between vertebrate hosts and vectors but also help to guide science- 
based programmes of disease surveillance, control and prevention (Kitron, 1998; Reisen, 2010).

As part of a recent, large study on the eco-epidemiology of Chagas disease (American human trypanosomiasis) in rural Argentina, spatial analysis was integrated with classic regression models to derive a risk map of community infestation by Triatoma infestans (Hemiptera: Reduviidae) - the main vector of the causative parasite in the 'Southern Cone' countries of South America. The study took place in the hyper-endemic Moreno district of Santiago del Estero province, within Argentina's Gran Chaco region (Vazquez-Prokopec et al., 2009). A local spatial statistic - the Getis-Ord $G I^{\star}(d)$ (Ord, 1995) - was applied to geo-referenced data on the domestic infestation of rural communities by $T$. infestans (Fig. 1). This allowed the precise locations of clusters or 'hot spots' of high-prevalence domestic infestation to be identified (Fig. 2). Communities located in neighbouring districts were included in the analysis, to account for any edge effects. Local clustering $\left[G^{\star}(d) .1 .96 ; P\right.$, 0.05 ] of the prevalence of domestic infestation was maximized at $25 \mathrm{~km}$, with a total of 47 communities (in the south-western corner of Moreno) belonging to a hot-spot of domestic infestation (Fig. 2). Maximum-likelihood logistic regression and multi-model inference (Burnham and Anderson, 2002) were then used to identify the environmental and demographic factors associated with the inclusion of a community in this hot-spot (Fig. 3). Such factors were derived from diverse remote sensors (Fig. 3; Ord, 1995; Kitron, 1998; Vazquez-Prokopec et al., 2009) or the results of geo-statistical analysis of census data (Fig. 2).

The best regression model included four factors - elevation, land-use (percentage covered by secondary forest and percentage deforested), land-surface temperature and the density of rural houses - as the most important factors predicting inclusion in a hot-spot of infestation. The best model correctly classified $90.1 \%$ of the 220 communities, with a sensitivity of $86.8 \%$ and a specificity of $91.3 \%$. The logistic-regression coefficients from the best model were then used to generate a predictive risk map, depicting the probability that each community was part of a $T$. infestans hot-spot (Fig. 4). The risk model not only predicted the location of the south-western hot-spot but also allowed the extent of the highrisk area for bug infestation to be estimated (at about $6000 \mathrm{~km}^{2}$, or $37.5 \%$ of the total area of Moreno). Given the limited resources available for surveillance and control of Chagas (and many other neglected tropical diseases), such spatially explicit, science-based risk maps are valuable tools since they can help identify high-risk areas, and improve resource allocation for targeted programmes of disease prevention and control (Kitron, 1998; Reisen, 2010).

When integrating epidemiological and remotely sensed data, a compromise between spatial and temporal resolution is often necessary (Kitron, 1998; Reisen, 2010). Regardless of the scale used to address a research or public-health question, the temptation is to extrapolate from fine-resolution data or to interpolate from coarse-resolution studies. In both cases, the relevance of the data collected and analyses conducted on one spatial level to other levels cannot be taken for granted. Spatial heterogeneity on the micro-scale may not be detected using coarse spatial resolution and, conversely, general patterns on the macro-scale may not be detected using fine spatial resolution. In addition, only if the biology and epidemiology of the system are well understood can the underlying processes modulating the patterns of occurrence and spatial distribution of vertebrate hosts, pathogens and vectors be inferred (Kitron, 1998; Reisen, 2010). 


\section{THE USE OF GEOGRAPHICAL INFORMATION SYSTEMS IN VACCINE- EFFICACY TRIALS}

The 'usual' deployment of a GIS is at the 'far' end of the disease spectrum, when transmission is already taking place - at which point a variety of indicators and variables can be mapped. Recently, however, the role of GIS in the prevention of several diseases, particularly vaccine-preventable tropical diseases, has been growing (Ali et al., 2005 b, 2009; Ali and Clemens, 2008; Sur et al., 2009). The increasing use of GIS in the design and execution of vaccine trials is probably a result of conceptual and methodological advances in geographical analysis (Ali et al., 2001). To create a GIS database for health studies and vaccine trials, the geographical co-ordinates of the population under surveillance - and other geographical features of interest — are collected (Ali et al., 2004; Khan et al., 2006). Such databases can help investigators in planning, designing, conducting, and analysing the data from vaccine trials.

\section{GIS in Planning and Logistic Support for a Trial}

A vaccine trial requires a study area with sufficient disease burden, adequate health-care centres to detect the target disease, and a system for the transportation of the vaccines (frequently within a cold chain). Knowledge about the population, the physical characteristics of the area and the local barriers to vaccine delivery and healthcare access are essential prerequisites for selecting a trial site. In cluster randomized trials, such as the trials of the Vi typhoid vaccine in Kolkata, India (Sur et al., 2009) and Karachi, Pakistan (Khan et al., 2006), it is necessary to define appropriate geographical clusters and understand both the population size and the disease burden at the cluster level. Between-cluster heterogeneity in disease burden may lead to bias in the estimate of protection offered by the vaccine. GIS can help in investigating the spatial pattern of the disease burden and then any significant heterogeneity in this indicator can be addressed during data analysis. This is one of the ways that Ali et al. (2009) used GIS while evaluating the efficacy of a cholera vaccine in Matlab, Bangladesh.

If vaccines are administered in the community, the daily vaccine requirement has to be predicted accurately, to allow shipping of the correct number of vaccine doses within the cold chain. The shipping of too few doses may result in under-utilized volunteers and undervaccination of the susceptible population whereas the shipping of too many doses requires the return of doses and increases the risk of a break in the cold chain. GIS can be used to define the clusters to be vaccinated during each day of vaccination, as well as the target population residing within the clusters. In Vietnam, a GIS was used to estimate the distance between specimen-collection centres and the centre for specimen storage (Ali et al., 2007).

\section{GIS in Trial Management}

Refusals and absentees are a common concern in vaccine trials. In an individually randomized trial, the non-compliant participants can be expected to be distributed among vaccinees and controls in a balanced fashion. This is not necessarily the case, however, in a cluster randomized trial, where 'nests' of refusals may exist. The identification of areas with relative high frequencies of non-compliance, during a vaccine campaign, can help investigators to target such areas for sensitization prior to the next day/round of vaccination and/or increased volunteer deployment during the next vaccinations. The prevalences of non-compliance are best depicted geographically. The GIS used by Ali et al. (2007), in a vaccine trial in Vietnam, helped in the identification and targeting of the areas that were worst affected by non-compliance. 
The distance to health facilities plays a vital role in healthcare-seeking behaviour, particularly in developing settings. In a vaccine trial, subjects are usually enrolled in a hospital-based system of passive surveillance. Compared with the other subjects, those who live far away from the target health facilities will be less likely to attend those facilities (Ali et al., 2007). Therefore, it is important to use enough health facilities, for enrollment and surveillance, to ensure that all subjects live conveniently close to at least one health facility involved in the trial. This requires knowledge of the spatial distributions of the population and the existing health facilities, of any barriers to movements, and, often, of any spatial barriers to the establishment of new health facilities. Sur et al. (2009) used a GIS to establish project health clinics in appropriate places, for a vaccine trial conducted in Kolkata, India. Use of a GIS enables determination of spatial metrics (e.g. costs and network distances) including those associated with the removal of impediments to healthcare provision. When resource constraints do not allow the establishment of new health facilities, GIS can provide the spatial information needed to delineate and create the best trial areas, and subsequently to analyse the trial data (Sur et al., 2009).

\section{GIS in Analysing Trial Data}

When measuring the protective efficacy of the candidate vaccine in an individually randomized trial, adjustments are usually made for the individual-level biological and socioeconomic risk factors (known or unknown) for the target disease. The results of several studies (Shouls et al., 1996; Diez-Roux et al., 1997; Waitzman and Smith, 1998; Pickett and Pearl, 2001) have shown that place can affect health outcome. Several ecological factors have been shown to influence vaccine efficacy (Emch et al., 2006), even in a small geographical area, indicating that, in estimating the efficacy of a vaccine, adjustments have to be made not only for the individual-level risk factors but also for the ecological-level factors. The latter are, in principle, less likely to be evenly distributed in space than the individual-level risk factors. Since a GIS can include measurements of ecological variables, it can also enhance the valid analysis of vaccine efficacy (Emch et al., 2006).

Conventionally, potential confounders and effect modifiers of vaccine efficacy are evaluated at an individual scale. While this is appropriate for biological factors (age, gender etc), other factors, such as socio-economic status, literacy, profession, water supply, sanitation and crowding, cannot be appropriately analysed at an individual scale (Emch et al., 2006). In a cluster randomized trial, potential confounders and effect modifiers of vaccine efficacy are evaluated on a cluster scale. Using GIS, ecological data can be estimated and included in the analyses (Twigg et al., 2000; Ali et al., 2002, 2005c).

\section{GIS in a Vaccine-safety Programme}

Real, perceived and unknown adverse events from vaccinations are a source of concern among parents and healthcare providers and can ultimately affect vaccination coverage. In the U.S.A., several computerized population databases, such as the Vaccine Adverse Event Reporting System (VAERS), exist to provide surveillance for detecting vaccine-related adverse effects. Such systems are, however, limited to only a few industrialized countries. Health planners in developing countries have very few prospectively collected data on vaccine safety, even though safety concerns are particularly relevant to such countries. There is a real need for population-based surveillance systems to be established in developing countries, both to monitor vaccination-related adverse events and to identify, accurately, the presence or absence of vaccination-linked medical conditions. In mid 2002, a large, GIS-linked database for monitoring vaccine-safety issues was created in a semi-rural province in central Vietnam (Ali et al., 2005a). The database provided a unique opportunity to evaluate the adverse effects related to measles vaccine, after addressing the spatial effects of hospitalization rate in the study area (Ali et al., 2003). 


\section{Concluding Comments on the Use of GIS in Vaccine Trials}

In conclusion, several issues of health are inherently spatial, and ignoring those issues in a vaccine trial may not be wise. Robust data on direct vaccine protection, as well as on safety and immunogenicity, are required by regulatory agencies before the licensing of a new vaccine can be considered. Such data are typically the only information that is used for product prescription information and advertising. GIS offer epidemiologists and planners a valuable new tool (Krieger, 2003), and the use of GIS in vaccine trials may help investigators improve their study design, management, analysis, and interpretation of data, enhancing the value and scientific quality of the trials.

\section{GIS IN SYSTEMS OF GLOBAL HEALTH INFORMATION FOR DISEASE CONTROL}

In 1995, the Pan American Health Organization (the World Heath Organization's Office for the Americas) launched an important initiative, to disseminate and encourage the use of GIS for analysis and problem-solving in epidemiology and public health (Castillo-Salgado, 1996). As part of this project - after it was realised that the available analysis tools were inadequate for GIS-based studies on tropical medicine and epidemiology and that there was a lack of integration between the statistical and epidemiological programs then in use - a public-domain software package named SIGEpi was developed (Martinez et al., 2001). The SIGEpi package offers simplified tools and interfaces, enabling most of the commonly used field-epidemiological and geographical analyses to be carried out efficiently, in support of decision-making in public health. The software was largely based on the MapObjects ${ }^{\mathrm{TM}}$ package (ESRI Inc, Redlands, CA). Its key functions include measures, for quantitative analysis in epidemiology, that are particularly useful in exploratory data analysis. It includes descriptive statistics, correlation analysis and simple and multiple linear regressions. Calculation of rates, ratios and proportions is also included, as well as the ability to make adjustments, using direct and indirect methods, and to perform spatial smoothing. A major advantage of SIGEpi is the provision of a set of very useful procedures used in public-health practice. These include identification of critical and priority areas, the development of a composite health index (such as basic unmet health needs or a poverty index), the identification and detection of spatial and time-space clusters, the measurement of the association between environmental exposure factors and health events (for case-control or cohort epidemiological studies), and methods for evaluating accessibility to health services (based on the radial-schemes technique), such as the estimation of linear origin-destination distances.

SIGEpi is currently used as an analytical tool for the surveillance and control of several key tropical diseases, including malaria in Brazil and some other countries of the Americas (Castillo-Salgado et al., 2000). It was also used in a project (which ran from 2003-2006) designed to prevent the re-introduction of DDT for malaria control in Mexico and Central America. The Ministries of Health of Mexico, Guatemala, Honduras, Costa Rica, Nicaragua, El Salvador and Panama, with the co-operation of several international agencies [PAHO/ WHO, the Global Environment Facility (GEF), the United Nations Environment Program (UNEP) and the North American Commission for Environmental Cooperation (CEC)], participated in a regional programme to evaluate and demonstrate sustainable alternatives to DDT in the control of malaria vectors. One component of this programme was the use of GIS to standardize, compile, integrate and interchange a digital cartographic infrastructure (data, methods and software), as a basis for analysing geographical data about vector control and DDT residuals. The main goal of this component was to contribute to the strengthening of the national technical capacities for malaria prevention and control (Najera et al., 2005). 
The epidemiological stratification of malaria risk was used to select the high-risk communities that were included in the project. A preparatory phase included local training in SIGEpi and the standardization and collection of GPS data on mosquito breeding sites and house proximities. A GIS-based epidemiology model was used as a platform for data collection, surveillance, analysis and evaluation. A series of thematic maps, developed in SIGEpi, showed cartographic layers of houses with malaria cases, streets, rivers, and concentric buffer zones that allowed the calculation of the numbers of preventive treatments needed to cover dwellings located within various distances $(50-250 \mathrm{~m})$ of the houses with malaria cases.

The results of this SIGEpi-based project demonstrated that the combination of epidemiological and GIS analysis provided an effective means of displaying levels of malaria risk and planning more effective interventions for malaria prevention and control. A more detailed description of the different components of this project can be found online (www.cec.org/files/pdf/POLLUTANTS/UNEPDDT_\%20brief_EN.pdf).

\section{GIS IN THE EPIDEMIOLOGY AND CONTROL OF HELMINTHIASES}

Helminthiases are some of the most common infections of humans. In sub-Saharan Africa, 740 million individuals are estimated to be infected with soil-transmitted helminths (Ascaris lumbricoides, Trichuris trichiura, and the hookworms Necator americanus and Ancylostoma duodenale; De Silva et al., 2003), 207 million have schistosomiasis (Schistosoma haematobium and S. mansoni; Steinmann et al., 2006), 50 million have lymphatic filariasis caused by Wuchereria bancrofti (Michael and Bundy, 1997), and 37 million have onchocerciasis as the result of Onchocerca volvulus infection (Basáñez et al., 2006). All of these helminth infections can be effectively treated with single-dose oral therapies that are safe and inexpensive, although retreatment, at periodic intervals, is often required (Richter, 2003; Gulani et al., 2007; Olsen, 2007; Taylor-Robinson et al., 2007; Keiser and Utzinger, 2008). The World Health Organization (WHO) has set a target to treat regularly, by 2010, at least $75 \%$ of all school-age children considered at risk of helminth-related morbidity (WHO, 2002). Currently, treatment is typically implemented through population-based programmes in which the schoolchildren or, via mass drug administrations (MDA), every eligible member of an at-risk population receives treatment.

There are several measures of helminth transmission that are valuable guides in the implementation of treatment programmes. The one most commonly measured, often during school or household surveys, is the point prevalence of infection (i.e. the proportion of individuals infected). Where different species of helminth overlap in their distributions, it is likely that many individuals will harbour co-infection with one of more species, and the prevalence of co-infection is another useful measure of infection. Another metric is the intensity of infection (i.e. the worm burden), which is estimated from quantitative counts of the helminth's eggs in faecal or urine samples or counts of microfilariae in bloodsmears.

These metrics provide an indirect measure of transmission intensity and the risk of morbidity.

Because of the ease of collecting prevalence data, the choice of where to implement control is typically based on whether the prevalence of infection exceeds some species-specific threshold (WHO, 2002). Twice-yearly treatments are generally recommended in areas where infection with soil-transmitted helminths and/or schistosomes exceeds 50\% (Bethony et al., 2006; Fenwick et al., 2006) whereas once-yearly treatments are recommended for effective control in areas with lower prevalences of schistosome infection and those with onchocerciasis or lymphatic filariasis (Zagaria and Savioli, 2002; Bethony et al., 2006; Fenwick et al., 2006; Hotez, 2007). 
The effective control of helminth infections in humans requires reliable estimates of the geographical distributions of such infections and the sizes of populations requiring an intervention (Brooker and Michael, 2000; Boatin and Richards, 2006; Brooker et al., 2006a; Molyneux, 2009). Although, for the purposes of planning control, nationwide survey or surveillance data are preferable, few endemic countries have suitable, detailed data. To address the paucity of data on helminth infections, research over the last decade has explored ways to maximise the usefulness of the data that are available, based on spatial mapping and prediction (Brooker and Michael, 2000; Brooker, 2002, 2007; Brooker et al., 2006a; Simoonga et al., 2009).

Most recently, these predictive approaches have employed Bayesian model-based geostatistics (MBG), in which classical geostatistics are embedded in the framework of a generalised linear model. The relationship and associated uncertainty between infection outcomes and covariates are estimated and the model is used to predict the outcome at unsampled locations (Diggle et al., 1998). This approach has the advantage, over traditional spatial-prediction methods, of providing a better handling of the uncertainty associated with predicting infection patterns.

In helminthology, MBG were initially used to model prevalences of infection at national (Clements et al., 2006a, 2009a; Diggle et al., 2007) and subnational levels (Raso et al., 2005, 2006a; Beck-Wörner et al., 2007). At the regional scale, MBG applications are documented in both East (Clements et al., 2010) and West Africa (Kelly-Hope et al., 2006; Clements et al., 2008). These applications enable areas to be stratified according to intervention strategy - for example, identifying those areas where prevalence exceeds 50\% (Clements et al., 2006a).

The first application of MBG for predicting intensity involved the fitting of a negativebinomial distribution to data, on the intensities of human infection with $S$. mansoni, collected in East Africa (Clements et al., 2006b). In West Africa, a regional multinomial model was built to identify areas with high prevalences of high-intensity $S$. haematobium infection (Clements et al., 2009b). A zero-inflated negative-binomial model for $S$. mansoni infection was also constructed for western Côte d'Ivoire (Vounatsou et al., 2009).

To date, two studies have employed MBG to predict the geographical distribution of helminth co-infections. Both studies investigated the spatial distribution of co-infection with S. mansoni and hookworm, the first at subnational scale in Côte d'Ivoire (Raso et al., 2006b) and the second at regional scale in the East African Great Lakes region (Brooker and Clements, 2009).

Predicted prevalence maps, including those derived from MBG, can be multiplied by electronic population-density maps to determine the numbers of individuals infected in each location; examples of this approach include Brooker et al. $(2006 a, b)$ and Clements et al. (2010).

\section{GIS FOR PANDEMIC PLANNING AND PREDICTION}

GIS and mapping systems are among the emerging technologies that are increasingly being used to build the new systems, of public-health information, needed for the 'real-time' surveillance of infectious diseases, including many tropical diseases (Albert et al., 2000).

Pandemics are intrinsically geographical, with infection often moving rapidly from one place to another and spanning large distances in doing so. The planning required to prepare for, or intervene in, pandemics involves an understanding of the spatial patterns of the transmission and spread of the pathogen involved. In the most recent global pandemic, of 
H1N1 influenza, GIS played a critical role in putting into motion a wide variety of locationbased analyses, from developing strategies for social distancing to implementing tactical vaccine-distribution logistics. GIS were used, by national, sub-state and local health jurisdictions around the world, to identify geographically those populations that were most at risk, to guide the local administration of vaccines, and, ultimately, to measure the effectiveness of the entire 'antipandemic' process. Being prepared for a pandemic means learning to use increasing amounts of geographically relevant information from a wide variety of non-standard sources — such as data supplied by volunteer or 'crowd' contributors. Analysis of the data - and identifying what the information actually means must also become more transparent, with many more disciplines being involved in the recommendations for action. When pandemics threaten, GIS software will also become ubiquitous and useful to a wider group of interested people, from epidemiologists and infectious-disease experts to social and medical practitioners, helping to pass the relevant data from specialised 'information works' to the aggressively health-seeking/informationseeking consumers. Spatial analysis, aided by sophisticated but easily accessed satellite imagery and image interpretation, will become a common 'cloud-computing' service (where the relevant software, applications and data will co-exist) that can be efficiently accessed, upon demand, from anywhere at any time. The future of successful disease surveillance and tracking in the years ahead will rely heavily on many of these contemporary approaches to data collection, data analysis and information dissemination (Khan and Skinner, 2003).

\section{CONCLUSIONS}

At the frontier of the digital-information revolution, GIS have emerged as a powerful means to assist public-health professionals in better understanding the epidemiological complexities of priority health conditions and diseases (Gatrell, 2002; Khan and Skinner, 2003).

Although the move from hand-drawn maps to mainframes to personal computers made GIS increasingly more accessible and usable, the optimal use of such systems remains a challenge. In many ways, GIS are already used to morph data into information and, sometimes, information into decision making (Devlin, 1999). The second of these steps has not yet been universally adopted, and this failure carries the danger of 'siloing' geographical data into specific disease interests. The solution may lie in 'going back while going forward': adopting the latest technology for the particular tropical-medicine problem of interest but integrating that technology, from the start, in decision making. The potential of GIS has yet to be revealed in at least two areas: a thematic one (i.e. policy-making) and, appropriately enough, a geographical one (i.e. under-developed settings). More and more ministries of health have a GIS unit, often supported, in part, by international organizations or research consortia. Unfortunately, the bulk of decision-making for tropical-disease control remains stubbornly tied to paper, tables and data that, if not geographically enabled, may not cross the threshold to improved policy and improved health outcomes.

In relatively recent history - at least since the time of the British physician and 'father' of epidemiology, John Snow (1813-1858) - tropical infectious disease has been a geographical entity, in that the characteristics of location can be used for epidemiology and disease detection, and also for planning a response (Koch, 2005). In an age where the mortality attributable to non-HIV infectious tropical disease is likely to diminish, new challenges of equity and inequity present themselves. Some result from the classical 'tropical diseases' and some from the diseases of poverty. Although the diseases of poverty can be found in the temperate climates of the western world as well as in the tropical, developing world, they are still diseases of place: highways and levees may divide the rich 
and poor as surely as oceans do. The characteristics and outcomes of tuberculosis, malnutrition and even cholera may differ markedly over surprisingly small distances.

It is probably among the world's poorest that the vast potential of GIS has most to be realised. Beyond the mere description of a problem, such geographical tools could be used to track and respond and to improve, sustain and scale-up interventions. The optimal use of GIS will require not only continued innovation in technology and application but also something that is not yet visible: a continuous flow of information between disciplines and across borders, focussed on the end result (whether that is the health of a single patient or that of a sub-Saharan nation). Although GIS can play a major role in an integrated solution, those proficient in the use of such systems will need to communicate a great deal more, across boundaries, than they do presently.

\section{Acknowledgments}

During the research described here, two of the authors (G. V.-P. and U. K.) were supported by awards from the U.S. National Institutes of Health/National Science Foundation Ecology of Infectious Disease programme (award R01 TW05836; funded by the Fogarty International Center), the U.S. National Institute of Environmental Health Sciences, the Research and Policy for Infectious Disease Dynamics programme of the U.S. Science and Technology Directorate, the U.S. Department of Homeland Security, and the Fogarty International Center, National Institutes of Health.

A University of Queensland Research Scholarship and an International Postgraduate Research Award (\#41795457) supported R.J.S.M., while A.C.A.C. was supported by an Australian National Health and Medical

\section{References}

Albert, DP.; Gesler, WM.; Levergood, B. Spatial Analysis, GIS and Remote Sensing. Chelsea, MI: Ann Arbor Press; 2000.

Ali M, Clemens J. Ecological aspects in vaccine trials. Expert Review of Vaccines. 2008; 7:279-281. [PubMed: 18393595]

Ali M, Emch M, Ashley C, Streatfield PK. Implementation of a medical geographic information system: concepts and uses. Journal of Health, Population and Nutrition. 2001; 19:100-110.

Ali M, Emch M, Donnay JP. Spatial filtering using a raster geographic information system: methods for scaling health and environmental data. Health and Place. 2002; 8:85-92. [PubMed: 11943581]

Ali M, Canh DG, Clemens JD, Park JK, von Seidlein L, Thiem VD, Tho LH, Trach DD. The vaccine data link in Nha Trang, Vietnam: a progress report on the implementation of a data base to detect adverse events related to vaccinations. Vaccine. 2003; 21:1681-1686. [PubMed: 12639490]

Ali M, Rasool S, Park JK, Saeed S, Ochiai RL, Nizami Q, Acosta CJ, Bhutta Z. Use of satellite imagery in the construction of a household GIS database for health studies in Karachi, Pakistan. International Journal of Health Geographics. 2004; 3:20. [PubMed: 15450121]

Ali M, Canh DG, Clemens JD, Park JK, von Seidlein L, Thiem VD, Tho LH, Trach DD. The Vaccine Safety Datalink Group. The use of a computerised database to monitor vaccine safety in Vietnam. Bulletin of the World Health Organization. 2005a; 83:604-610. [PubMed: 16193545]

Ali M, Emch M, von Seidlein L, Yunus M, Sack DA, Rao M, Holmgren J, Clemens JD. Herd immunity conferred by killed oral cholera vaccines in Bangladesh: a reanalysis. Lancet. 2005b; 366:44-49. [PubMed: 15993232]

Ali M, Park JK, Thiem VD, Canh DG, Emch M, Clemens JD. Neighborhood size and local geographic variation of health and social determinants. International Journal of Health Geographics. 2005c; 4:12. [PubMed: 15927082]

Ali M, Thiem VD, Park JK, Ochiai RL, Canh DG, Danovaro-Holliday MC, Kaljee LM, Clemens JD, Acosta CJ. Geographic analysis of vaccine uptake in a cluster randomized controlled trial in Hue, Vietnam. Health and Place. 2007; 13:577-578. [PubMed: 17254831]

Ali M, Emch M, Yunus M, Clemens J. Modeling spatial heterogeneity of disease risk and evaluation of the impact of vaccination. Vaccine. 2009; 27:3724-3729. [PubMed: 19464555] 
Basáñez MG, Pion SD, Churcher TS, Breitling LP, Little MP, Boussinesq M. River blindness: a success story under threat? PLoS Medicine. 2006; 3:e371. [PubMed: 17002504]

Beck-Wörner C, Raso G, Vounatsou P, N'Goran EK, Rigo G, Parlow E, Utzinger J. Bayesian spatial risk prediction of Schistosoma mansoni infection in western Côte d'Ivoire using a remotely-sensed digital elevation model. American Journal of Tropical Medicine and Hygiene. 2007; 76:956-963. [PubMed: 17488922]

Bethony J, Brooker S, Albonico M, Geiger SM, Loukas A, Diemert D, Hotez PJ. Soil-transmitted helminth infections: ascariasis, trichuriasis, and hookworm. Lancet. 2006; 367:1521-1532. [PubMed: 16679166]

Boatin BA, Richards FO Jr. Control of onchocerciasis. Advances in Parasitology. 2006; 61:349-394. [PubMed: 16735169]

Brooker S. Schistosomes, snails and satellites. Acta Tropica. 2002; 82:207-214. [PubMed: 12020894]

Brooker S. Spatial epidemiology of human schistosomiasis in Africa: risk models, transmission dynamics and control. Transactions of the Royal Society of Tropical Medicine and Hygiene. 2007; 101:1-8. [PubMed: 17055547]

Brooker S, Clements AC. Spatial heterogeneity of parasite co-infection: Determinants and geostatistical prediction at regional scales. International Journal for Parasitology. 2009; 39:591597. [PubMed: 19073189]

Brooker S, Michael E. The potential of geographical information systems and remote sensing in the epidemiology and control of human helminth infections. Advances in Parasitology. 2000; 47:245288. [PubMed: 10997209]

Brooker S, Rowlands M, Haller L, Savioli L, Bundy DA. Towards an atlas of human helminth infection in sub-Saharan Africa: the use of geographical information systems (GIS). Parasitology Today. 2000; 16:303-307. [PubMed: 10858650]

Brooker S, Clements AC, Bundy DA. Global epidemiology, ecology and control of soil-transmitted helminth infections. Advances in Parasitology. 2006a; 62:221-261. [PubMed: 16647972]

Brooker S, Clements AC, Hotez PJ, Hay SI, Tatem AJ, Bundy DA, Snow RW. The co-distribution of Plasmodium falciparum and hookworm among African schoolchildren. Malaria Journal. 2006b; 5:99. [PubMed: 17083720]

Burnham, KP.; Anderson, DR. Model Selection and Multimodel Inference: a Practical Informationtheoretic Approach. New York, NY: Springer; 2002.

Castillo-Salgado C. Use of geographic information systems in epidemiology (GIS-Epi). Epidemiological Bulletin. 1996; 17 (1):1-6.

Castillo-Salgado, C.; Loyola-Elizondo, E.; Vidaurre-Arenas, M.; Martínez-Piedra, R.; GassibeKlarian, P.; Klarian, JM.; González-Cruz, R.; González-Castañeda, M.; BeasNava, JA. Geographic Information System in Health: Basic Concepts. Washington, DC: Pan American Health Organization; 2000.

Clements AC, Lwambo NJ, Blair L, Nyandindi U, Kaatano G, Kinung'hi S, Webster JP, Fenwick A, Brooker S. Bayesian spatial analysis and disease mapping: tools to enhance planning and implementation of a schistosomiasis control programme in Tanzania. Tropical Medicine and International Health. 2006a; 11:490-503. [PubMed: 16553932]

Clements AC, Moyeed R, Brooker S. Bayesian geostatistical prediction of the intensity of infection with Schistosoma mansoni in East Africa. Parasitology. 2006b; 133:711-719. [PubMed: 16953953]

Clements AC, Garba A, Sacko M, Touré S, Dembelé R, Landouré A, Bosqué-Oliva E, Gabrielli AF, Fenwick A. Mapping the probability of schistosomiasis and associated uncertainty, West Africa. Emerging Infectious Diseases. 2008; 14:1629-1632. [PubMed: 18826832]

Clements AC, Bosqué-Oliva E, Sacko M, Landouré A, Dembelé R, Traoré M, Coulibaly G, Gabrielli AF, Fenwick A, Brooker S. A comparative study of the spatial distribution of schistosomiasis in Mali in 1984-1989 and 2004-2006. PLoS Neglected Tropical Diseases. 2009a; 3:e431. [PubMed: 19415108]

Clements AC, Firth S, Dembelé R, Garba A, Touré A, Sacko M, Landouré A, Bosqué-Oliva E, Barnett AG, Brooker S, Fenwick A. Use of Bayesian geostatistical prediction to estimate local variations 
in Schistosoma haematobium infection in western Africa. Bulletin of the World Health Organization. 2009b; 87:921-929. [PubMed: 20454483]

Clements AC, Deville MA, Ndayishimiye O, Brooker S, Fenwick A. Spatial co-distribution of neglected tropical diseases in the East African Great Lakes region: revisiting the justification for integrated control. Tropical Medicine and International Health. 2010; 15:198-207. [PubMed: 20409287]

De Silva NR, Brooker S, Hotez PJ, Montresor A, Engels D, Savioli L. Soil-transmitted helminth infections: updating the global picture. Trends in Parasitology. 2003; 19:547-551. [PubMed: 14642761]

Devlin, K. Infosense: Turning Information Into Knowledge. New York, NY: W. H. Freeman; 1999.

Diez-Roux AV, Nieto FJ, Muntaner C, Tyroler HA, Comstock GW, Shahar E, Cooper LS, Watson RL, Szklo M. Neighborhood environments and coronary heart disease: a multilevel analysis. American Journal of Epidemiology. 1997; 146:48-63. [PubMed: 9215223]

Diggle PJ, Moyeed RA, Tawn JA. Model-based geostatistics. Applied Statistics. 1998; 47:299-350.

Diggle PJ, Thomson MC, Christensen OF, Rowlingson B, Obsomer V, Gardon J, Wanji S, Takougang I, Enyong P, Kamgno J, Remme JH, Boussinesq M, Molyneux DH. Spatial modelling and the prediction of Loa loa risk: decision making under uncertainty. Annals of Tropical Medicine and Parasitology. 2007; 101:499-509. [PubMed: 17716433]

Emch M, Ali M, Park JK, Yunus M, Sack DA, Clemens JD. Relationship between neighborhood-level killed oral cholera vaccine coverage and protective efficacy: evidence for herd immunity. International Journal of Epidemiology. 2006; 35:1044-1050. [PubMed: 16723370]

Fenwick A, Rollinson D, Southgate V. Implementation of human schistosomiasis control: challenges and prospects. Advances in Parasitology. 2006; 61:567-622. [PubMed: 16735173]

Gatrell, AC. Geographies of Health. Oxford, U.K: Blackwell; 2002.

Gulani A, Nagpal J, Osmond C, Sachdev HP. Effect of administration of intestinal anthelmintic drugs on haemoglobin: systematic review of randomised controlled trials. British Medical Journal. 2007; 334:1095. [PubMed: 17434954]

Hotez PJ. Control of onchocerciasis — the next generation. Lancet. 2007; 369:1979-1980. [PubMed: 17574078]

Keiser J, Utzinger J. Efficacy of current drugs against soil-transmitted helminth infections: systematic review and meta-analysis. Journal of the American Medical Association. 2008; 299:1937-1948. [PubMed: 18430913]

Kelly-Hope LA, Diggle PJ, Rowlingson BS, Gyapong JO, Kyelem D, Coleman M, Thomson MC, Obsomer V, Lindsay SW, Hemingway J, Molyneux DH. Negative spatial association between lymphatic filariasis and malaria in West Africa. Tropical Medicine and International Health. 2006; 11:129-135. [PubMed: 16451336]

Khan, OA.; Skinner, R. Geographic Information Systems and Health Applications. Hershey, PA: IGP Press; 2003.

Khan MI, Ochiai RL, Hamza HB, Sahito SM, Habib MA, Soofi SB, Bhutto NS, Rasool S, Puri MK, Ali M, Wasan SM, Khan MJ, Elyazeed RA, Ivanoff B, Galindo CM, Pang T, Donner A, von Seidlein L, Acosta CJ, Clemens JD, Nizami SQ, Bhutta ZA. Lessons and implications from a mass immunization campaign in squatter settlements of Karachi, Pakistan: an experience from clusterrandomized double-blinded controlled trial. Trials. 2006; 7:17. [PubMed: 16725026]

Kitron U. Landscape ecology and epidemiology of vector-borne diseases: tools for spatial analysis. Journal of Medical Entomology. 1998; 35:435-445. [PubMed: 9701925]

Koch, T. Cartographies of Disease: Maps, Mapping and Medicine. Redlands, CA: ESRI Press; 2005.

Krieger N. Place, space, and health: GIS and epidemiology. Epidemiology. 2003; 14:384-385. [PubMed: 12843759]

Martinez R, Vidaurre M, Najera P, Loyola E, Castillo-Salgado C, Eisner C. SIGEpi: geographic information system in epidemiology and public health. Epidemiological Bulletin. 2001; 22 (3):45. [PubMed: 11797235]

Michael E, Bundy DA. Global mapping of lymphatic filariasis. Parasitology Today. 1997; 13:472476. [PubMed: 15275135] 
Molyneux DH. Filaria control and elimination: diagnostic, monitoring and surveillance needs. Transactions of the Royal Society of Tropical Medicine and Hygiene. 2009; 103:338-341. [PubMed: 19181357]

Najera P, Martinez R, Vidaurre M. From sketch to digital maps: a geographic information system (GIS) model and application for malaria control without the use of pesticides. Epidemiological Bulletin. 2005; 26 (1):8-10. [PubMed: 16578882]

Olsen A. Efficacy and safety of drug combinations in the treatment of schistosomiasis, soil-transmitted helminthiasis, lymphatic filariasis and onchocerciasis. Transactions of the Royal Society of Tropical Medicine and Hygiene. 2007; 101:747-758. [PubMed: 17481681]

Ord JAG. Local spatial autocorrelation statistics: distributional issues and an application. Geographical Analysis. 1995; 27:287-306.

Pickett K, Pearl M. Multilevel analyses of neighborhood socioeconomic context and health outcomes: a critical review. Journal of Epidemiology and Community Health. 2001; 55:111-122. [PubMed: 11154250]

Raso G, Matthys B, N'Goran EK, Tanner M, Vounatsou P, Utzinger J. Spatial risk prediction and mapping of Schistosoma mansoni infections among schoolchildren living in western Côte d'Ivoire. Parasitology. 2005; 131:97-108. [PubMed: 16038401]

Raso G, Vounatsou P, Gosoniu L, Tanner M, N'Goran EK, Utzinger J. Risk factors and spatial patterns of hookworm infection among schoolchildren in a rural area of western Côte d'Ivoire. International Journal for Parasitology. 2006a; 36:201-210. [PubMed: 16259987]

Raso G, Vounatsou P, Singer BH, N'Goran EK, Tanner M, Utzinger J. An integrated approach for risk profiling and spatial prediction of Schistosoma mansoni- hookworm coin-fection. Proceedings of the National Academy of Sciences of the United States of America. 2006b; 103:6934-6939. [PubMed: 16632601]

Reisen W. Landscape epidemiology of vector-borne diseases. Annual Review of Entomology. 2010; 55:461-483.

Richter J. The impact of chemotherapy on morbidity due to schistosomiasis. Acta Tropica. 2003; 86:161-183. [PubMed: 12745135]

Shouls S, Congdon P, Curtis S. Modeling inequality in reported long term illness in the UK: combining individual and area characteristics. Journal of Epidemiology and Community Health. 1996; 50:366-376. [PubMed: 8935472]

Simoonga C, Utzinger J, Brooker S, Vounatsou P, Appleton CC, Stensgaard AS, Olsen A, Kristensen TK. Remote sensing, geographical information system and spatial analysis for schistosomiasis epidemiology and ecology in Africa. Parasitology. 2009; 136:1683-1693. [PubMed: 19627627]

Steinmann P, Keiser J, Bos R, Tanner M, Utzinger J. Schistosomiasis and water resources development: systematic review, meta-analysis, and estimates of people at risk. Lancet Infectious Diseases. 2006; 6:411-425. [PubMed: 16790382]

Sur D, Ochiai RL, Bhattacharya SK, Nirmal K, Ganguly NK, Ali M, Manna B, Dutta S, Donner A, Kanungo S, Park JK, Puri MK, Kim DR, Dutta D, Bhaduri B, Acosta CJ, Clemens JD. A clusterrandomized effectiveness trial of Vi typhoid vaccine in India. New England Journal of Medicine. 2009; 361:335-344. [PubMed: 19625715]

Taylor-Robinson, DC.; Jones, AP.; Garner, P. Cochrane Database of Systematic Reviews 2007. Chichester, U.K: John Wiley \& Sons; 2007. Deworming Drugs for Treating Soil-transmitted Intestinal Worms in Children: Effects on Growth and School Performance; p. Art. No. CD000371

Twigg L, Moon G, Jones K. Predicting small-area health-related behaviour: a comparison of smoking and drinking indicators. Social Science and Medicine. 2000; 50:1109-1120. [PubMed: 10714931]

Vazquez-Prokopec GM, Spillmann C, Zaidenberg M, Kitron U, Gürtler RE. Cost-effectiveness of Chagas disease vector control strategies in northwestern Argentina. PLoS Neglected Tropical Diseases. 2009; 3:e363. [PubMed: 19156190]

Vounatsou P, Raso G, Tanner M, N'Goran EK, Utzinger J. Bayesian geostatistical modelling for mapping schistosomiasis transmission. Parasitology. 2009; 136:1695-1705. [PubMed: 19490724]

Waitzman N, Smith K. Phantom of the area: poverty area residence and mortality in the United States. American Journal of Public Health. 1998; 88:973-976. [PubMed: 9618634] 
World Health Organization. Technical Report Series No 912. Geneva: WHO; 2002. Prevention and Control of Schistosomiasis and Soil-Transmitted Helminthiasis.

Zagaria N, Savioli L. Elimination of lymphatic filariasis: a public-health challenge. Annals of Tropical Medicine and Parasitology. 2002; 96 (Suppl 2):S3-S13. [PubMed: 12630389] 


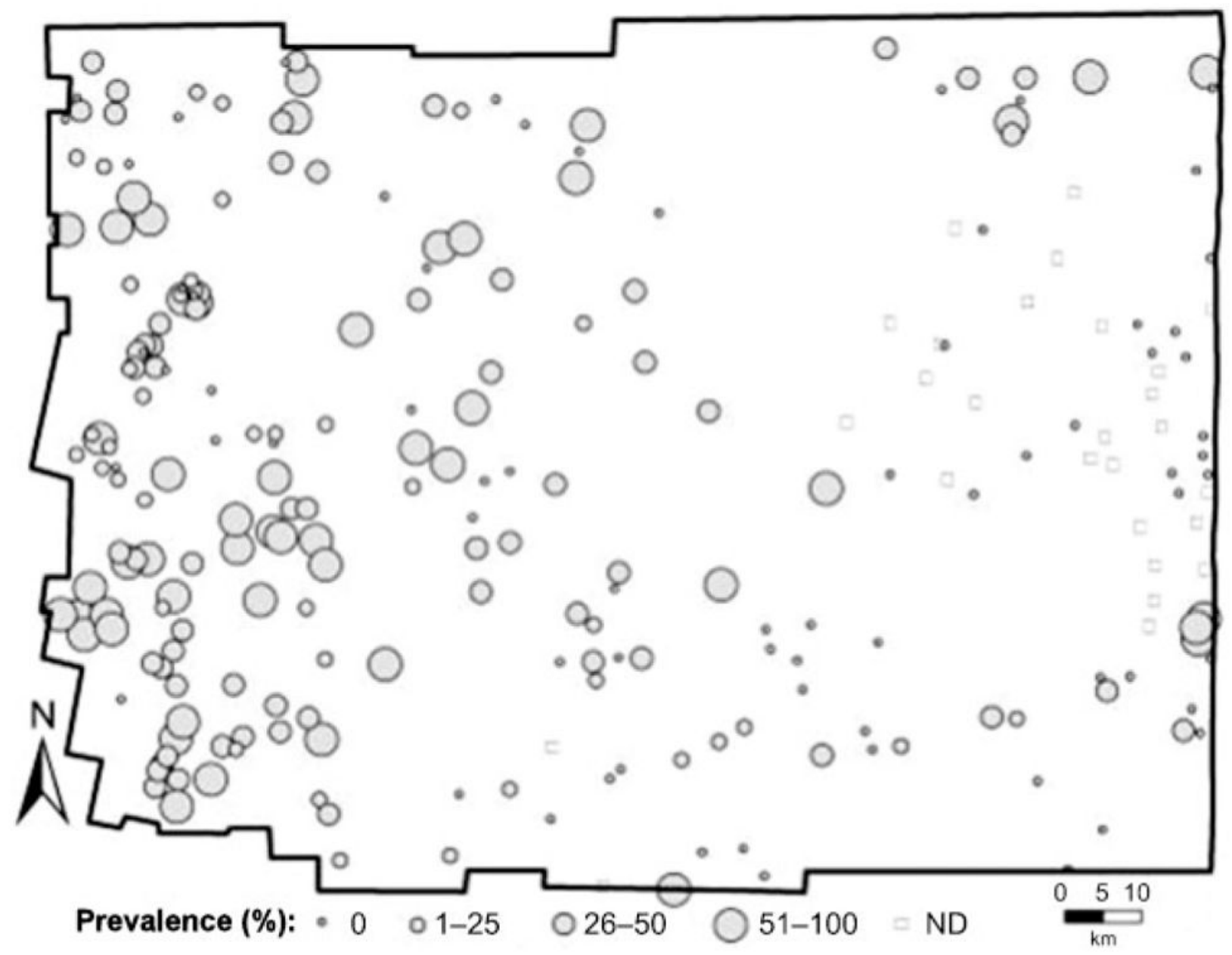

FIG. 1.

Geo-referenced data of domestic infestation by Triatoma infestans, the main vector of the parasite that causes Chagas disease, in rural communities of the district of Moreno (Santiago del Estero, Argentina), as provided by the Argentinean Ministry of Health. ND, Not determined. 
<smiles>NC1CC1</smiles>

0

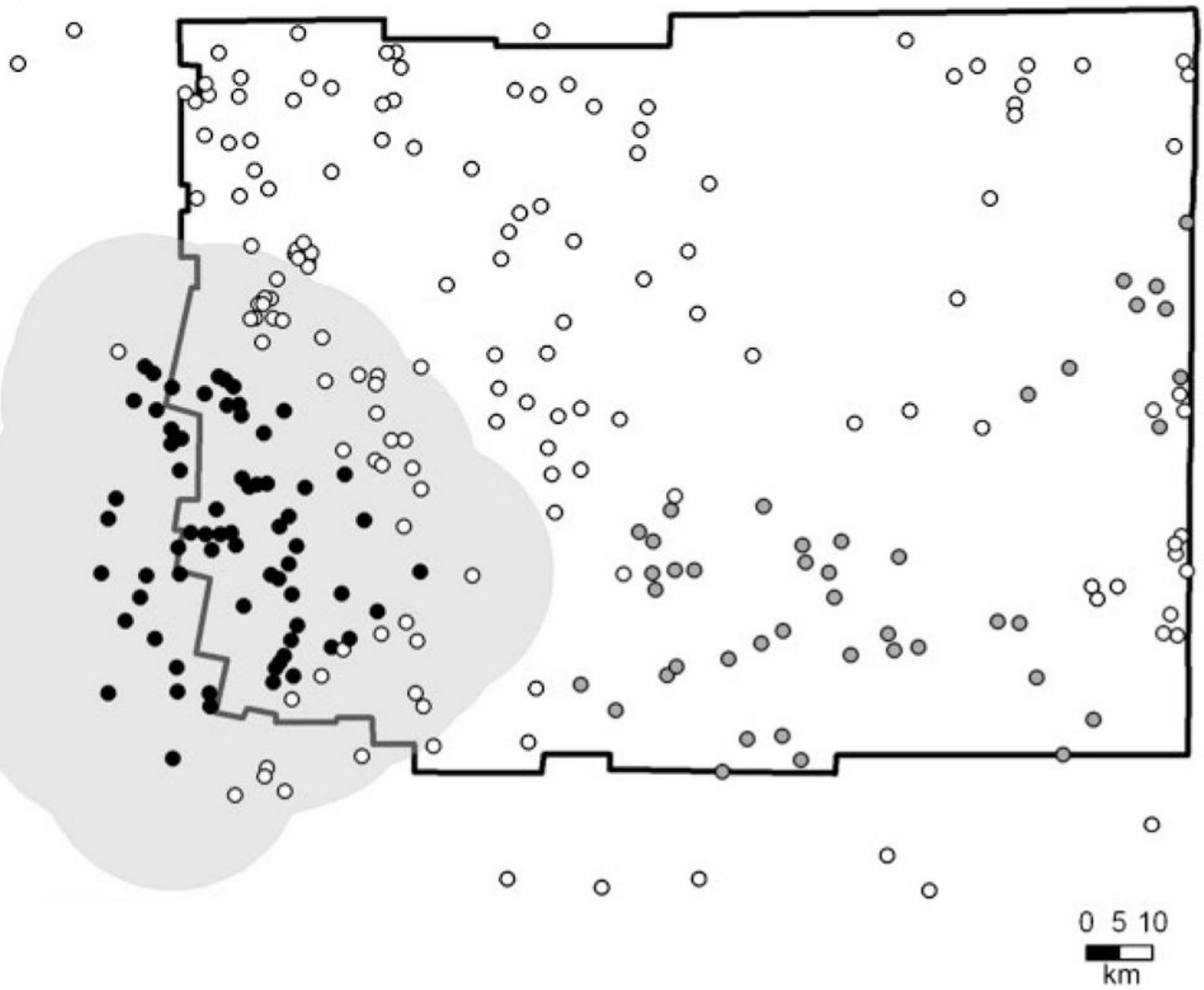

FIG. 2.

Results of analysis in which the Getis-Ord statistic, $G^{\star}(d)(\mathrm{Ord}, 1995)$, was used to detect hot-spots for domestic infestation with Triatoma infestans $(*)$, the symbols indicating locations with positive $(\bullet)$, negative $(\bullet)$ and no clustering $(\bigcirc)$. 

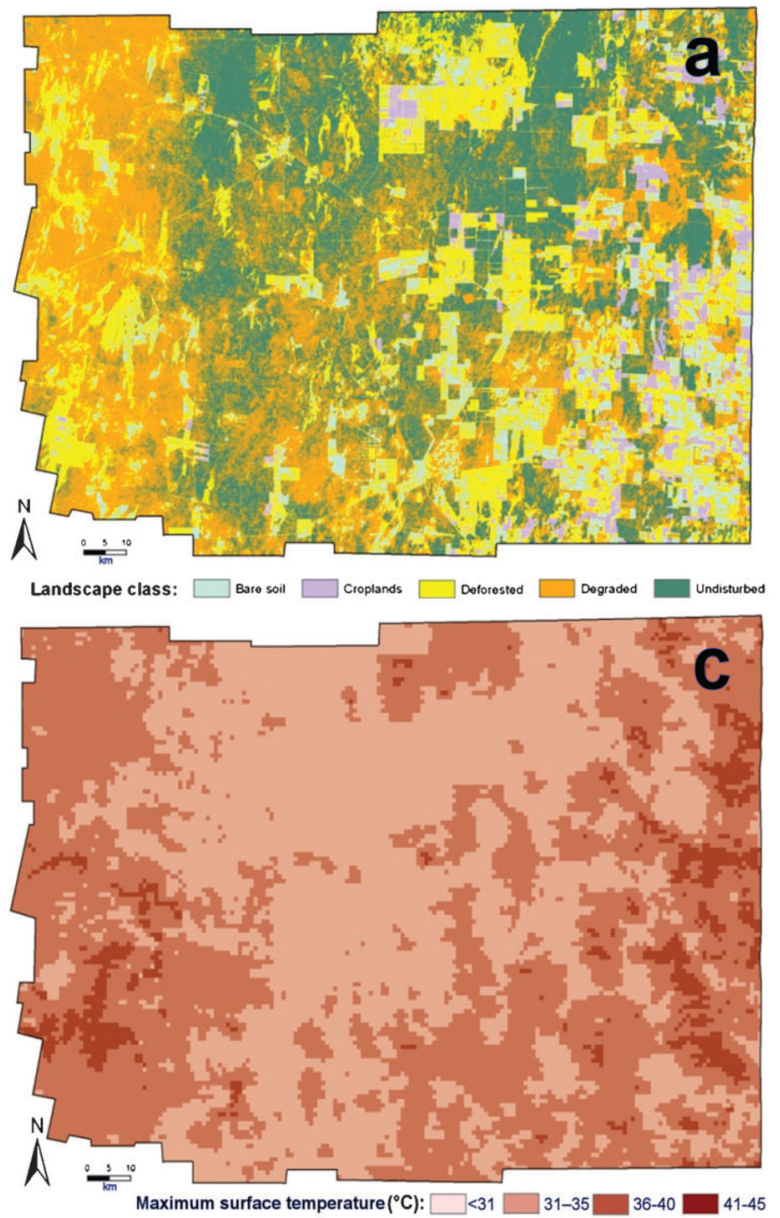

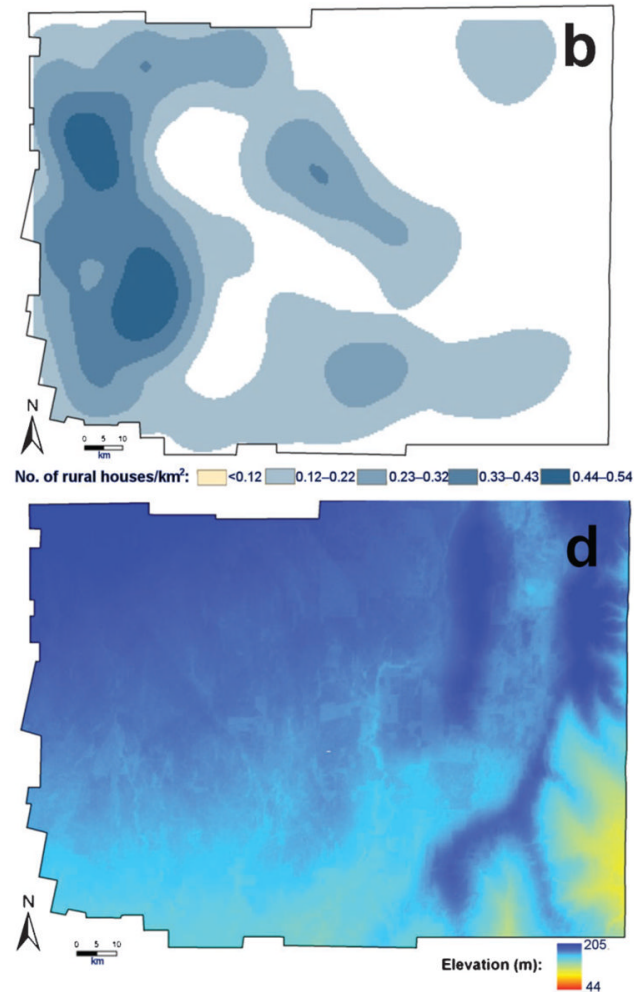

FIG. 3.

The four remotely sensed environmental or demographic factors - land-use [(a); collected by the U.S. National Aeronautics and Space Administration's (NASA's) Landsat 5 TM], density of rural houses [(b); kernel density estimation], land-surface temperature [(c); collected by NASA's Moderate Resolution Imaging Spectroradiometer (MODIS)] and terrain elevation [(d); collected by NASA's Shuttle Radar Topography Mission (SRTM)] used in a maximum-likelihood logistic regression to predict the inclusion of communities in an infestation hot-spot. 


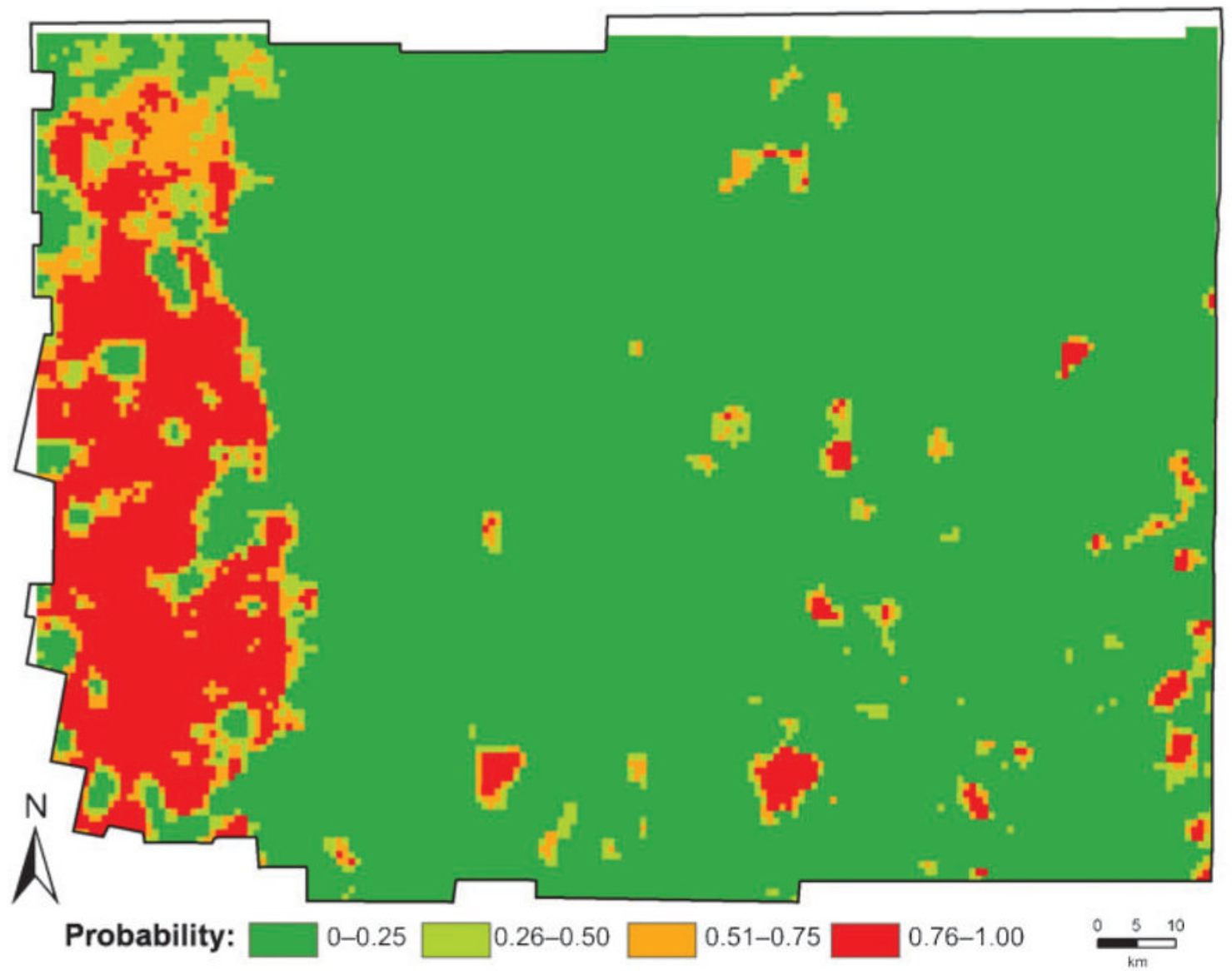

FIG. 4.

Risk map for domestic infestation by Triatoma infestans in the district of Moreno, based on the coefficients from the best logistic-regression model. 